\title{
Análise da nova legislação em relação a polos de educação a distância
}

\author{
Francieli Carvalho Castro* \\ João Mattar \\ Elenita Oliveira ${ }^{* * *}$
}

\section{Resumo}

Este artigo analisa como a nova legislação brasileira aborda os polos de educação a distância. Trata-se de uma pesquisa bibliográfica centrada basicamente em dois documentos: o Decreto nº 9.057 , de 25 de maio de 2017, e a Portaria Normativa $n^{\circ} .11$, de 20 de junho de 2017. Seu objetivo é discutir os pontos desses documentos legais que regulamentam as atividades dos polos de apoio presencial na educação a distância. São também analisadas algumas reações a esses documentos. $\mathrm{O}$ artigo conclui que a flexibilização instaurada pela nova legislação poderá ser positiva para o desenvolvimento da educação brasileira, mas traz também desafios de controle de qualidade, por exemplo, em relação aos polos de educação a distância.

Palavras-chave: Educação a distância. Legislação de EaD. Polos de EaD.

\section{Analysis of new legislation on distance education learning centers Abstract}

This article analyzes how the new Brazilian legislation addresses the distance education learning centers in the country. It is a bibliographical research centered basically on two documents: Decree No. 9,057, dated

\footnotetext{
* Mestranda em Educação e Novas Tecnologias no Centro Universitário Internacional Uninter. E-mail: carvalho83.fran@hotmail.com

** Professor no Mestrado em Educação e Novas Tecnologias do Centro Universitário Internacional Uninter e no TIDD (PUC-SP). E-mail: joaomattar@ gmail.com

*** Professora no Centro Universitário Internacional Uninter. E-mail: elenita_ oliveira@hotmail.com
} 
May 25, 2017, and Normative Ordinance No. 11, dated June 20, 2017. Its purpose is to discuss the points on these legal documents that regulate the activities of the learning centers in distance education. Some reactions to these documents are also analyzed. The article concludes that the flexibility introduced by the new legislation may be positive for the development of Brazilian education, but also brings quality control challenges, for example, in relation to learning centers.

Keywords: Distance Education. Distance Education legislation. Learning centers.

\section{Análisis de la nueva legislación en relación a los polos de educación a distancia}

\section{Resumen}

Este artículo analiza cómo la nueva legislación brasileña aborda los polos de educación a distancia en el país. Se trata de una investigación bibliográfica centrada básicamente en dos documentos: el Decreto nº 9.057, de 25 de mayo de 2017, y la Portaria Normativa nº. 11, del 20 de junio de 2017. Su objetivo es discutir los puntos de esos documentos legales que regulan las actividades de los polos de apoyo presencial en la educación a distancia. También se analizan algunas reacciones a estos documentos. El artículo concluye que la flexibilización instaurada por la nueva legislación podría ser positiva para el desarrollo de la educación brasileña, pero trae también desafíos de control de calidad, por ejemplo, en relación a los polos de educación a distancia.

Palabras clave: Educación a distancia. Legislación de educación a distancia. Polos de educación a distancia.

\section{Introdução}

O ano de 2017 foi marcado pela publicação de alguns documentos legais que alteraram radicalmente o cenário e o horizonte da educação a distância $(\mathrm{EaD})$ no Brasil. Entre as principais mudanças, destaca-se a flexibilização em relação à criação de polos de apoio presencial. Este artigo propõe-se a analisar em que aspectos essa nova legislação altera a regulamentação em relação aos polos EaD. 
Foi realizada uma pesquisa bibliográfica centrada basicamente em dois documentos: o Decreto no 9.057, de 25 de maio de 2017 (BRASIL, 2017a), e a Portaria Normativa no 11, de 20 de junho de 2017 (BRASIL, 2017b). O objetivo é apresentar e discutir os pontos desses documentos legais que fazem referência ao funcionamento de polos de EaD. São também discutidas reações a esses documentos, tanto positivas quanto negativas.

A próxima seção apresenta os aspectos da nova legislação em relação aos polos de EaD. A seção seguinte discute a argumentação do PDC 733/2017 - Projeto de Decreto Legislativo de Sustação de Atos Normativos do Poder Executivo, que propõe sustar a Portaria $\mathrm{n}^{\mathrm{o}}$ 11. Por fim, a conclusão reflete sobre os desafios de controle de qualidade que acompanham a nova legislação.

\section{Polos de educação a distância na nova legislação}

Diante dos efeitos gerados pela transformação da política educacional em educação a distância, mais especificamente o Decreto no 9.057 (BRASIL, 2017a) e a Portaria nº 11 (BRASIL, 2017b), que trouxeram diversas mudanças na legislação da EaD no Brasil, inclusive no que diz respeito aos polos de apoio presencial, discutiremos nesta seção as principais alterações propostas nesses documentos legais.

O Decreto no 9.057 regulamenta o artigo 80 da Lei de Diretrizes e Bases da Educação, que versa sobre a educação a distância. A partir dessa nova legislação, as instituições de ensino superior (IES) passam a ter autonomia para criar polos, não dependendo mais de avaliação do Ministério da Educação (MEC) para autorizar seu funcionamento, como ocorria nos processos anteriores ao Decreto $n^{\circ}$ 9.057. Anteriormente, para que uma IES pudesse autorizar a oferta de cursos em um novo polo de sua rede, era necessário passar por um processo de cadastramento de novo polo, o que demandava uma série de exigências institucionais e de parceiros, e que podia levar até dois anos aguardando a comissão avaliativa e a publicação da portaria de funcionamento no Diário Oficial da União. 
Apenas após finalizado o processo, a IES podia liberar o funcionamento do polo. Nesse sentido, o Decreto em questão trouxe mais agilidade ao processo:

Art. 16. A criação de polo de educação a distância, de competência da instituição de ensino credenciada para a oferta nesta modalidade, fica condicionada ao cumprimento dos parâmetros definidos pelo Ministério da Educação, de acordo com os resultados de avaliação institucional.

$\int 1^{\circ}$ As instituições de ensino deverão informar a criação de polos de educação a distância e as alterações de seus endereços ao Ministério da Educação, nos termos a serem estabelecidos em regulamento. (BRASIL, 2017a).

Ao mesmo tempo em que o MEC permite mais autonomia às IES no processo de abertura de novos polos, também as condiciona a serem responsáveis integrais na fiscalização de sua rede, exigindo o cumprimento dos requisitos dispostos no regimento para o funcionamento de polos. Sendo assim, a instituição de ensino superior poderá criar um polo e só depois informar ao MEC:

Art. 13 - A IES deverá informar, no Sistema e-MEC, seus polos de EaD criados, no prazo máximo de sessenta dias, a contar da expedição do ato próprio, mantendo atualizados os dados de pessoal, infraestrutura física e tecnológica, prevista no art. 11, documentação que comprove disponibilidade dos imóveis e eventuais contratos de parceria. (BRASIL, 2017b).

A condição de abertura e registro no MEC de novo polo pelas IES, em períodos não concomitantes um ao outro, denota a necessidade de discussão das políticas públicas no que se refere à qualidade estrutural de funcionamento de rede de polos das IES e do próprio posicionamento do mercado educacional. Nesse contexto, a legislação restringe a abertura de polos a uma quantidade anual, que cada instituição de ensino superior pode criar, baseada no seu Conceito Institucional (CI) atribuído pelo MEC em eventos anteriores:

Art. 12 - As IES credenciadas para a oferta de cursos superiores a distância, poderão criar polos $\mathrm{EaD}$ por ato próprio, observando os quantitativos 
máximos definidos no quadro a seguir, considerados o ano civil e o resultado do Conceito Institucional mais recente:

\begin{tabular}{|c|c|}
\hline Conceito Institucional & Quantitativo anual de Polos \\
\hline 3 & 50 \\
\hline 4 & 150 \\
\hline 5 & 250 \\
\hline
\end{tabular}

$[\ldots]$

$\int 2^{\circ}-\mathrm{A}$ ausência de atribuição de Conceito Institucional para uma IES equivalerá, para fins de quantitativos de polos EaD a serem criados por ano, ao Conceito Institucional igual a 3. (BRASIL, 2017b).

A partir dessa regulamentação, pode-se imaginar um aumento significativo no número de polos de EaD no Brasil (o que já vem ocorrendo), associado à desconcentração do poder econômico, como prevê Rodrigo Capelato, diretor executivo do Semesp - Sindicato das Entidades Mantenedoras de Estabelecimentos de Ensino superior no Estado de São Paulo:

Capelato afirma que se as instituições criarem 25\% dos polos aos quais elas têm direito - considerando que, dependendo do Conceito Institucional, é possível abrir de 50 a 250 polos -, a concentração nas mãos dos 10 maiores grupos poderá cair de $80 \%$ (estimativa para 2017) para 52\% em 2018, chegando a 35\% em 2027. (KUZUYABU, 2017).

Outra condição descrita no documento norteador é que a extinção de um polo não possibilitará o aumento do número de polos que a instituição pode criar naquele ano:

Art. 17

$[\ldots]$

$\int 2^{\circ}-\mathrm{A}$ extinção de polo de EaD pela IES ou pela Seres não gerará a recomposição de quantitativo anual para fins de criação de novos polos. Ou seja, a extinção de um polo não aumenta o número de polos que a IES pode criar naquele ano. (BRASIL, 2017b). 
Por sua vez, a troca de endereço de um polo caracterizará a baixa de um registro e a criação de um novo, sem afetar, portanto, o total de polos a que a IES tem direito de criar naquele ano:

Art. 16 - A alteração de endereço de polo de $\mathrm{EaD}$ se processará como substituição de polo, ocasionando a baixa do código original, a geração de um novo código, restrito ao município de funcionamento, e a transferência dos cursos de $\mathrm{EaD}$ do primeiro para o segundo código. (BRASIL, 2017b).

Nessas circunstâncias, podemos considerar o critério condicionante no trâmite de polos ativos, pois uma vez realizado o registro do local, mesmo que eventualmente não venha a entrar em funcionamento, será contabilizado na lista de polos ativos do e-MEC, sistema eletrônico de acompanhamento dos processos que regulam a educação superior no Brasil.

Anteriormente, o processo de avaliação dos polos de apoio presencial das IES seguia os critérios avaliativos dispostos no Instrumento de Avaliação de Polos, do INEP, em que era selecionada uma amostra de polos de determinada instituição, sendo então destinadas comissões para a avaliação in loco. Após a divulgação do Decreto $n^{\circ} 9.057 / 2017$, a avaliação ficará centrada na sede da instituição, incluindo automaticamente, a partir de agora, a avaliação dos polos e dos ambientes profissionais:

Art. $5^{\circ}$ - As avaliações in loco nos processos de EaD serão concentradas no endereço sede da IES.

$\int 1^{\circ}-\mathrm{A}$ avaliação in loco no endereço sede da IES visará à verificação da existência e adequação de metodologias, infraestrutura física, tecnológica e de pessoal que possibilitem a realização das atividades previstas no PDI e no Projeto Pedagógico do Curso - PPC.

$\int 2^{\circ}$ - Durante a avaliação in loco no endereço sede, as verificações citadas no $\int 1^{\circ}$ também devem ser realizadas, por meio documental ou com a utilização de recursos tecnológicos disponibilizados pelas IES, para os Polos de EaD previstos no PDI e nos PPC, e os ambientes profissionais utilizados para estágio supervisionado e atividades presenciais. (BRASIL, 2017b). 
Mediante o novo cenário avaliativo que está sendo construído, mais concentrado nas sedes das IES, pode-se prever que será cobrada uma quantidade de recursos e documentos atualizados que permitam às comissões realizarem a avaliação institucional completa, possibilitando assim inclusive acesso aos polos de apoio presencial.

Outro item bastante aguardado pelas IES envolvia a regulamentação das bibliotecas nos polos. A partir do novo Decreto, as bibliotecas digitais são permitidas, de modo diferente do que já acontecia, quando os polos precisavam ter bibliotecas físicas com inúmeros exemplares de livros, o que se tornava financeiramente inviável especialmente quando sua estrutura física era pequena, e, além disso, a gestão dessas bibliotecas era muito complexa:

Art. 11

$[\ldots]$

VI - acervo físico ou digital de bibliografias básica e complementar (BRASIL, 2017b).

Em termos territoriais, finalmente as IES poderão investir em polos internacionais, desde que sigam as políticas educacionais dos países parceiros, em consonância com o regulamento brasileiro, oferecendo a possibilidade de estudo para milhares de brasileiros que residem em países diversos e desejam realizar um curso superior na modalidade a distância.

Art. $5^{\circ} \mathrm{O}$ polo de educação a distância é a unidade acadêmica e operacional descentralizada, no País ou no exterior, para o desenvolvimento de atividades presenciais relativas aos cursos ofertados na modalidade a distância. (BRASIL, 2017a).

\section{Reações contra a nova legislação}

A publicação do Decreto e especialmente da Portaria causou reações em alguns setores, como a área de Saúde, que vem se posicionando há tempo contra a oferta de graduação a distância em seus cursos. Nessa direção, em agosto de 2017 o deputado fe- 
deral Orlando Silva (PCdoB) propôs um Projeto de Decreto Legislativo de Sustação de Atos Normativos do Poder Executivo (PDC 733/2017). Seu propósito é sustar a Portaria 11.

A redação do Projeto é bastante simples:

\section{O Congresso Nacional decreta:}

Art. $1^{\circ}$ Fica sustada a Portaria $n^{\circ} 11$, de 20 de junho de 2017, republicada em 21 de junho de 2017, do Ministério da Educação, que estabelece normas para o credenciamento de instituições e a oferta de cursos superiores a distância, em conformidade com o Decreto n. 9.057, de 25 de maio de 2017.

Art. $2^{\circ}$ Este decreto legislativo entra em vigor na data de sua publicação (SILVA, 2017, p. 1).

Mas é seguida de uma justificação com quatro páginas. Inicialmente, o texto recapitula alguns documentos que regulamentavam a EaD no Brasil e breves dados sobre o crescimento da área. Há então uma crítica às "distorções” associadas a esse crescimento, com menção explícita (e longa) aos cursos na área da Saúde. Há também críticas ao Decreto, em relação à EaD no Ensino Médio, chegando-se finalmente à Portaria.

Há uma crítica inicial: "Ilustra o excesso de flexibilização da normativa a possibilidade de que as Instituições de educação superior (IES) possam ofertar cursos por EAD mesmo sem ter credenciamento para ministrar cursos presenciais na área" (SILVA, 2017, p. 4), mas na verdade a permissão para a existência de IES voltada exclusivamente para a oferta de EaD consta do Decreto:

Art. 11. As instituições de ensino superior privadas deverão solicitar credenciamento para a oferta de cursos superiores na modalidade a distância ao Ministério da Educação.

$[\ldots]$

$\int 2^{\circ}$ É permitido o credenciamento de instituição de ensino superior exclusivamente para oferta de cursos de graduação e de pós-graduação lato sensu na modalidade a distância.

$\int 3^{\circ}$ A oferta de curso de graduação é condição indispensável para a manutenção das prerrogativas do credenciamento de que trata o $\int 2^{\circ}$. 
(BRASIL, 2017a).

Há então no Projeto uma menção específica aos polos de EaD:

[...] Ademais, passa a não ser mais necessária a aprovação prévia do MEC para a abertura de polos EAD. O principal parâmetro basear-se-á no CI (conceito institucional), indicador de qualidade calculado anualmente após a visita de técnicos do MEC às instalações da instituição de ensino; entretanto, as visitas presenciais de avaliação, antes realizadas nas sedes das IES e nos polos, serão realizadas apenas nas sedes. A IES com CI 3 poderão criar até 50 polos por ano; as com CI 4 poderão criar 150 e as com CI 5 poderão abrir até 250 novos polos de EAD/ano. Já as instituições públicas de ensino estarão automaticamente credenciadas para a oferta de cursos a distância e passarão pelo recredenciamento em até cinco anos após a oferta do primeiro curso por EAD. (SILVA, 2017, p. 4).

\section{E então o texto do Projeto conclui:}

Este são apenas alguns exemplos decorrentes do novo procedimento oficial quanto à EAD, que nos parece beirar a irresponsabilidade, pois certamente não resultará em proveito nem para os alunos e nem para o país. Portanto, este PDC tem o objetivo de sustar de imediato os efeitos desta Portaria $\mathrm{n}^{\circ}$ 11, de 20 de junho de 2017 (republicada em 21 de junho de 2017), que estabelece normas para o credenciamento de instituições e a oferta de cursos superiores a distância, em conformidade com o Decreto $\mathrm{n}^{\circ}$ 9.057, de 25 de maio de 2017, antes que um mal maior e irreversível ocorra no campo da formação em educação superior do país. (SILVA, 2017, p. 5).

Como é possível observar, apesar de seu linguajar pomposo, o Projeto não apresenta praticamente qualquer tipo de justificativa para a sustação da Portaria 11. Além de indicação estatística de que os cursos de graduação de EaD na área de Saúde são oferecidos primordialmente pelo setor privado, há uma rápida menção de que "necessariamente demandam contato presencial durante a fase de formação profissional" - o que, é importante lembrar, não deixa de ocorrer nos cursos considerados de EaD pela legislação brasileira, já que disciplinas podem também ser ministradas presencialmente, 
além de atividades e encontros presenciais. Fora isso, simplesmente frases de efeito como: "junto com a expansão, vieram as distorções", "nos parece beirar a irresponsabilidade, pois certamente não resultará em proveito nem para os alunos e nem para o país" e "antes que um mal maior e irreversível ocorra no campo da formação em educação superior do país". Um Projeto, portanto, que carece de argumentos.

O PDC 733/2017 está no momento em tramitação ordinária na Câmara dos Deputados, mas pelo que foi analisado, não parece ter fundamentação mínima para prosseguir, sendo então provável que o Decreto e a Portaria analisados neste artigo continuem válidos, regulando assim os polos de apoio presencial na EaD em nosso país.

\section{Considerações finais}

Há um reconhecimento de que a flexibilização instaurada pela nova legislação poderá contribuir para o desenvolvimento da educação brasileira. A excessiva burocracia para a solicitação de autorização de funcionamento de polos de educação a distância é um dos pontos que foi reduzido com esses novos documentos legais. Ademais, as visitas para a autorização dos polos demoravam às vezes mais de dois anos, demonstrando que o MEC não tinha estrutura para fazer esse tipo de trabalho, além de os investimentos realizados pelas IES ficarem congelados por todo esse período, sendo ainda necessária a manutenção dos locais, já que os polos não podiam funcionar antes da autorização.

Por sua vez, cabe reconhecer que essa flexibilização traz desafios ao MEC e a outros órgãos e associações envolvidos com educação a distância, no sentido de garantir a qualidade do ensino para os alunos. A Operação EaD (COFEN, 2015), por exemplo, detectou inúmeras irregularidades em polos de apoio presencial em cursos de Enfermagem a distância no Brasil.

O Conselho Federal de Enfermagem, com base nas informações dos fiscais dos Departamentos de Fiscalização dos Conselhos Regionais de 
Enfermagem, sobre os polos de apoio presenciais, presentes em todos Estados da Federação, pode inferir que o controle dos Polos de Apoio Presencial, feito pelo MEC, não está garantindo a qualidade das atividades dos Cursos a Distância para o Bacharelado em Enfermagem e provavelmente, de nenhum outro curso na área da saúde. Não garantem as condições mínimas legalmente exigidas, nem tampouco serviços adequados e suficientes para atender aos docentes e acadêmicos em suas demandas e necessidades, para a formação profissional do Enfermeiro.

Estes Polos não apresentaram a infraestrutura física e tecnológica mínima, como laboratórios de anatomia, bioquímica, fisiologia, microbiologia, imunologia, parasitologia, entre outros, com microscópios, estufas, fotômetros, equipamentos, insumos e vidrarias, necessários para as aulas práticas exigidas por lei. Também não foram encontrados, na maioria dos polos, laboratórios específicos de Enfermagem, imprescindíveis à formação do Enfermeiro.

$[\ldots]$

As condições encontradas pelos fiscais em todo território nacional, nos Polos de Apoio Presenciais deixam explícito que a avaliação desenvolvida pelo MEC por amostragem e sem definir o quantitativo de acadêmicos não garante segurança e qualidade na formação. Questionamos como os Conselhos Regionais de Enfermagem poderão garantir segurança ou qualidade na assistência de Enfermagem prestada a população por esses profissionais? Portanto, fica questionada por este Conselho a eficiência da atuação fiscalizatória desenvolvida, no âmbito dos Cursos de Enfermagem, pelo MEC nas Instituições de Ensino Superior. (COFEN, 2015).

Embora reconhecendo a legitimidade da preocupação do COFEN com a qualidade do ensino de Enfermagem, entendemos, assim como a Associação Brasileira de Educação a Distância, que "qualquer crítica à metodologia do trabalho de credenciamento de polos de EaD, em Enfermagem ou em qualquer outro curso superior a distância, deva ser feita aos órgãos responsáveis, e não a uma modalidade de educação" (ABED, 2017), pois problemas semelhantes podem ocorrer, também, em cursos presenciais.

É necessário, de qualquer maneira, que sejam desenvolvidos instrumentos e critérios de avaliação de qualidade não apenas para polos de EaD, como também para a educação a distância e mesmo a educação em geral, mas que simultaneamente sejam garantidos re- 
cursos suficientes para que esse trabalho de fiscalização não freie o desenvolvimento do setor, como vinha ocorrendo nos últimos anos. Nesse sentido, a nova legislação é menos paternalista e centralizadora, delegando às próprias IES parte da responsabilidade pelo controle de qualidade de seus polos de EaD, e considerando que a fiscalização das sedes, a análise da documentação e, quando necessário, visitas in loco, serão suficientes para avaliar a qualidade dos cursos e dos polos. Com sua implementação, nos próximos anos, será possível avaliar com mais clareza os efeitos positivos e negativos dessa decisão.

\section{Referências}

ABED - Associação Brasileira de Educação a Distância. Educação a Distância faz mal à saúde? 17 fev. 2017. Disponível em: <http://abed.org.br/arquivos/ Educacao_Distancia_faz_mal_saude.pdf $>$.

BRASIL. Casa Civil. Decreto n. 9.057, de 25 de maio de 2017. Regulamenta o art. 80 da Lei $n^{\circ} .9 .394$, de 20 de dezembro de 1996, que estabelece as diretrizes e bases da educação nacional. Diário Oficial da União, Brasília, DF, n. 100, 26 maio 2017a, Seção 1, p. 3.

BRASIL. Ministério da Educação. Portaria Normativa nº 11, de 20 de junho de 2017. Estabelece normas para o credenciamento de instituições e a oferta de cursos superiores a distância, em conformidade com o Decreto n'. 9.057, de 25 de maio de 2017. Diário Oficial da União, Brasília, DF, nº 117, 21 jun. 2017b, Seção 1, p. 9 .

COFEN. Relatório consubstanciado da Operação EaD Cursos de Graduação em Enfermagem em resposta ao MPF, 21 out. 2015. Disponível em: $<$ http://www.cofen.gov.br/relatorio-consubstanciado-da-operacao-ead-cursosde-graduacao-em-enfermagem-em-resposta-ao-mpf_35188.html>.

KUZUYABU, Marina. O futuro da educação a distância. Ensino Superior, 221, 14 ago. 2017. Disponível em: < http://www.revistaensinosuperior.com.br/o-futuro-da-educacao-distancia/ $>$.

SILVA, Orlando. PDC 733/2017 - Projeto de Decreto Legislativo de Sustação de Atos Normativos do Poder Executivo, 16 ago. 2017, p. 1-5. Disponível em: <http://www.camara.gov.br/proposicoesWeb/fichadetramitacao?idProposi$\mathrm{caO}=2148252>$.

Submetido em: 31-3-2018

Aceito em: 2-4-2018 